\title{
Modified Halloysite Nanotubes: Nanoarchitectures for Enhancing the Capture of Oils from Vapor and Liquid Phases
}

\author{
Giuseppe Cavallaro, Giuseppe Lazzara,* Stefana Milioto, Filippo Parisi, and Vincenzo Sanzillo \\ Dipartimento di Fisica e Chimica, Università degli Studi di Palermo, Viale delle Scienze, pad. 17, 90128 Palermo, Italy \\ Supporting Information
}

\begin{abstract}
We prepared hybrid halloysite nanotubes (HNT/sodium alkanoates) in which the inner cavity of the nanoclay was selectively modified. Physicochemical studies evidenced the interactions between HNT and sodium alkanoates, ruled out clay exfoliation, quantified the amount of the loaded substance, and showed an increase of the total net negative charge, allowing us to obtain rather stable aqueous nanoclay dispersions. These dispersions were exploited as inorganic micelles to capture hydrocarbon and aromatic oils in the vapor and liquid states and were revealed to be nonfoaming but very efficient in encapsulating oils. Here, we have fabricated biocompatibile and low-cost inorganic micelles that can be exploited for industrial applications on a large scale.
\end{abstract}

KEYWORDS: halloysite, gas absorption, inorganic micelles, hydrocarbon solubilization

\section{INTRODUCTION}

For a long time, clay minerals, which are present in all types of sediments and sedimentary rocks, have been an object of scientific interest. Among them are the nanoclays, like imogolite and halloysite that both have a hollow tubular shape, which have a particular relevance for materials design. Imogolite, $\mathrm{Al}_{2} \mathrm{SiO}_{3}(\mathrm{OH})_{4}$, possesses an external diameter of ca. $25 \AA$ and an internal diameter of ca. $10 \AA^{1}{ }^{1}$ In spite of its interesting structure, imogolite shows a certain toxicity, which may limit its applications. ${ }^{2}$ Halloysite nanotubes (HNTs), $\mathrm{Al}_{2} \mathrm{Si}_{2} \mathrm{O}_{5}(\mathrm{OH})_{4}$. $2 \mathrm{H}_{2} \mathrm{O}$, possess a coil structure with an external diameter of ca. $50 \mathrm{~nm}$ and an internal diameter of ca. $15 \mathrm{~nm}$. The different chemistry at each surface offers the opportunity to control the selective interaction with ionic molecules. ${ }^{3,4}$ Recent studies proved that HNTs are ecological, biocompatible, and dispersible in water even at very high concentrations where they can form liquid crystalline phases. ${ }^{5,6}$ HNTs are abundant all over the world and consequently are available at low cost. All of these features (i.e., chemical structure and sustainable cost and biocompatibility) make HNTs very appealing for several purposes. Two main application fields can be identified. The first one concerns the use of HNTs as an additive for polymers to increase the mechanical resistance and to confer an active response ability to external stimuli. ${ }^{7-11}$ The second one deals with the suitability of the HNT cavity for catalysis ${ }^{12}$ and drug release. ${ }^{6}$ In this case, the modification of the HNT internal surface $^{13,14}$ was tuned to promote the affinity between nanotubes and target molecules. Very few studies are available on the enhanced solubilization of hydrophobic compounds exhibited by a modified HNT cavity. ${ }^{14,15}$

In fact, the preparation of organic/inorganic hybrid materials based on HNTs may be of interest in terms not only because of their sustainability and eco-compatibility but also because they satisfy the demands of several applications. The modification of HNTs is an attractive and big challenge, with the goal being (1) to produce rather stable dispersions for applications where nanocontainers and nanocarriers are required to oppose the sedimentation of pristine HNTs and (2) to direct molecular species into the internal space to fabricate the desired nanostructures for the purposes of interest.

In this work, we designed, prepared, and physicochemically characterized HNT/sodium alkanoates hybrids. Because their inner surface is positively charged and external surface is negatively charged over a wide $\mathrm{pH}$ range, ${ }^{6}$ we chose anionic compounds to make a selective hydrophobic modification to the cavity. Among various anionic surfactants, we selected sodium alkanoates obtained from the neutralization of fatty acids, which are biocompatible. Moreover, these surfactants are available with different hydrophilic-hydrophobic balances. We employed sodium undecanoate, sodium dodecanoate, and sodium tetradecanoate to tune and manipulate the degree of the hydrophobicity of the nanotubes core. Thermogravimetry, SEM, and FTIR spectroscopy were used to define the composition and morphology of the as-prepared hybrid materials. Dynamic light scattering, $\zeta$ potential, and turbidimetry allowed us to investigate the stability of their aqueous dispersions. These hybrids successfully entrap aliphatic and aromatic hydrocarbons, prototypes of hydrophobic contaminants and solvents, from gas and liquid phases. The developed biocompatible inorganic micelles are appealing for industrial

Received: October 23, 2013

Accepted: December 6, 2013

Published: December 6, 2013 

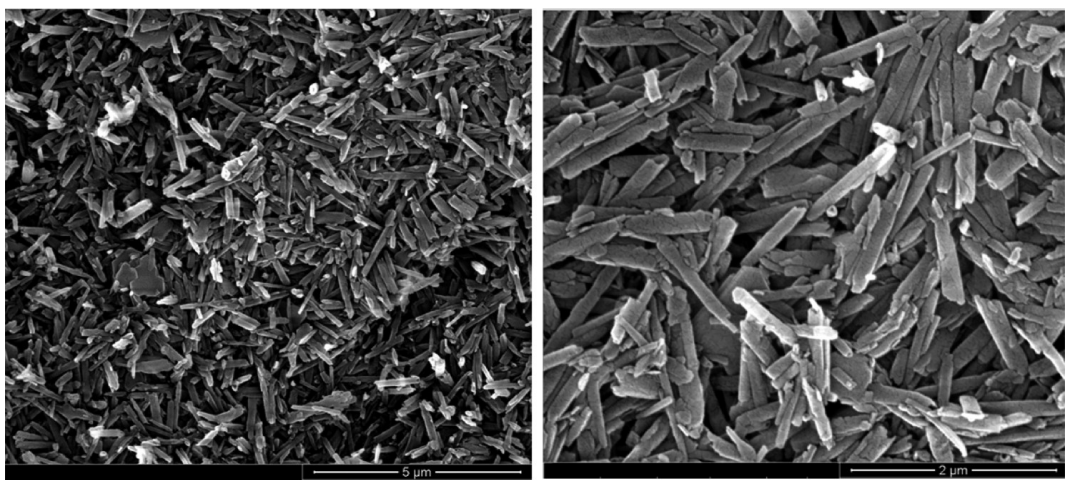

Figure 1. SEM micrographs for $\mathrm{HNT} / \mathrm{NaC} 12$.

applications such as detergency. At the same time, they might play the role of conventional micelles, which is well-known to enhance oil solubilization, and inorganic builders. Intriguingly, these nanohybrids are nonfoaming, and although they are very efficient, they contain a surfactant concentration below the critical concentration at which the detergent ability emerges.

\section{MATERIALS AND METHODS}

Halloysite nanotubes (HNTs), sodium undecanoate ( $\mathrm{NaC} 11)$, sodium dodecanoate $(\mathrm{NaC12})$, sodium tetradecanoate $(\mathrm{NaC14})$, and toluene were from Aldrich, and $n$-decane was from Fluka. All of the products were used as received. Water from reverse osmosis (Elga model option 3) with a specific resistivity higher than $1 \mathrm{M} \Omega \mathrm{cm}$ was used.

Preparation of Functionalized Nanotubes. Aqueous surfactant solutions were prepared by dissolving $5 \mathrm{~g}$ of surfactant $(\mathrm{NaC} 11$ or $\mathrm{NaC12}$ ) in $250 \mathrm{~cm}^{3}$ of water. Then, $5 \mathrm{~g}$ of HNT were added, and the obtained dispersion was magnetically stirred for $48 \mathrm{~h}$ at $20^{\circ} \mathrm{C}$. Successively, the dispersion was centrifuged to recover the functionalized material. The latter was washed with water several times until the water used in the washing reached the surface tension value of pure water $\left(72 \mathrm{mN} \mathrm{m}^{-1}\right)$. This procedure ensures that eventually free surfactant is no longer present and that the encapsulated surfactant is not released at least within 1 month. The same procedure was followed for $\mathrm{NaC14}$, but because of its low solubility in water $(330.8$ $\mathrm{mg} \mathrm{dm}{ }^{-3}$ ), the HNT was added by maintaining the same HNT/ surfactant weight ratio as for other surfactants and dissolving $0.075 \mathrm{~g}$ of $\mathrm{NaC} 14$ into $250 \mathrm{~cm}^{3}$ of water.

Thermogravimetry (TGA). Experiments were performed using a Q5000 IR apparatus (TA Instruments) under a nitrogen flow of 25 $\mathrm{cm}^{3} \min ^{-1}$ for the sample and $10 \mathrm{~cm}^{3} \mathrm{~min}^{-1}$ for the balance. The explored temperature interval ranged between 25 and $900{ }^{\circ} \mathrm{C}$ at a heating rate of $10{ }^{\circ} \mathrm{C} \mathrm{min}-1$. By recording the temperature dependence of mass loss (TG), the first-order differentiation curves of mass loss to temperature (DTG) were determined. The decomposition temperature $\left(T_{\mathrm{d}}\right)$ was taken at the maximum of the DTG peaks. The percentages of moisture loss at $120{ }^{\circ} \mathrm{C}\left(\mathrm{MD}_{120}\right)$ and of the residual matter at $900{ }^{\circ} \mathrm{C}\left(\mathrm{MR}_{900}\right)$ were determined from the TG curves.

IR Spectroscopy. The IR spectra were registered at ambient temperature in the range between 500 and $4000 \mathrm{~cm}^{-1}$ using an FT-IR spectrometer (Frontier, PerkinElmer). The spectral resolution was 2 $\mathrm{cm}^{-1}$. Each sample was prepared with $\mathrm{KBr}$.

Dynamic Light Scattering (DLS). The measurements were performed at $18.0 \pm 0.1{ }^{\circ} \mathrm{C}$ in a sealed cylindrical scattering cell at a scattering angle of $90^{\circ}$ using a Brookhaven Instrument apparatus composed of an BI-9000AT correlator and a $\mathrm{He}-\mathrm{Ne}$ laser $(75 \mathrm{~mW})$ at a wavelength $(\lambda)$ of $632.8 \mathrm{~nm}$.

Dispersions were prepared by using water filtered by a Millipore filter with a $0.45 \mu \mathrm{m}$ pore size.

For all of the systems, the field-time autocorrelation functions were well-described by a monoexponential decay function, which provides the decay rate $(\Gamma)$ correlated to the apparent diffusion coefficient $D=$
$\Gamma / q^{2}$, where $q=4 \pi n \lambda^{-1} \sin (\theta / 2)$ is the scattering vector in which $n$ is the refractive index of water and $\theta$ is the scattering angle.

$\zeta$ Potential. $\zeta$-Potential measurements were carried out with of a Zetasizer Nano-ZS (Malvern Instruments) at $25.0 \pm 0.1{ }^{\circ} \mathrm{C}$.

Turbidimetry. The transmittance as a function of time of the aqueous dispersions of $\mathrm{HNT} / \mathrm{NaC} 11, \mathrm{HNT} / \mathrm{NaC} 12, \mathrm{HNT} / \mathrm{NaC} 14$, and HNT $\left(1 \% \mathrm{w} \mathrm{w}^{-1}\right)$ was measured at $25.0 \pm 0.1{ }^{\circ} \mathrm{C}$ using an Analytic Jena Specord S 600 BU UV-vis spectrophotometer. The experiments were performed at a wavelength of $600 \mathrm{~nm}$, where no absorption bands were detected.

Isotherm of Adsorption. The ability of HNT/NaC11, HNT/ $\mathrm{NaC12}$, and $\mathrm{HNT} / \mathrm{NaC} 14$ to entrap toluene dissolved in water was monitored in the following way. Different amounts of HNT/surfactant were added to a fixed quantity of water saturated with toluene. The dispersions were stirred and equilibrated for 1 week. The concentration of residual toluene was determined by measuring the absorption spectra at $25.0 \pm 0.1{ }^{\circ} \mathrm{C}$ at wavelengths between 190 and $600 \mathrm{~nm}$ using an Analytic Jena Specord S $600 \mathrm{BU}$, with toluene presenting a peak at $261 \mathrm{~nm}$.

Surface Tension. A programmable tensiometer (KSV Sigma 70) equipped with a Wilhelmy plate was employed at $25.0 \pm 0.1{ }^{\circ} \mathrm{C}$. Each surface tension value is the average of three determinations, and its precision is $0.05 \mathrm{dyn} \mathrm{cm}^{-1}$. The amount of $n$-decane was chosen so that it would form a film on the water surface of ca. $1 \mathrm{~mm}$ and would be ca. $0.4 \mathrm{~g}$ of $n$-decane per $100 \mathrm{~g}$ of water. Before each measurement, the system was gently stirred for $2 \mathrm{~min}$.

Scanning Electron Microscopy (SEM). The morphology of the obtained materials was studied using an ESEM FEI QUANTA 200F microscope. Before each experiment, the surface of the sample was coated with gold in argon by means of an Edwards sputter coater S150A to avoid charging under the electron beam. The measurements were carried out in high-vacuum mode $\left(<6 \times 10^{-4} \mathrm{~Pa}\right)$ for simultaneous secondary electron, the energy of the beam was $30 \mathrm{kV}$, and the working distance was $10 \mathrm{~mm}$. Minimal electron dose conditions were used to avoid damage to the sample.

\section{RESULTS AND DISCUSSION}

Physicochemical Studies of HNT/Surfactant in the Solid State. We prepared the hybrid HNT/surfactant materials by developing an easy strategy to ensure that both the inner cavity was modified with anionic surfactant by allowing an ionic exchange and that the prepared materials were free of unadsorbed surfactant. The physicochemical characterization evidenced the success of the procedure.

As occurs for clays with a lamellar structure, like kaolin, the surface modification with the surfactants may result in clay exfoliation, ${ }^{16}$ which in the specific case of halloysite may induce a derolling coil with the loss of the hollow cylinder mesostructure. Because of this possibility, we performed SEM micrographs of $\mathrm{HNT} / \mathrm{NaC} 12$ and $\mathrm{HNT} / \mathrm{NaC} 14$, which were 

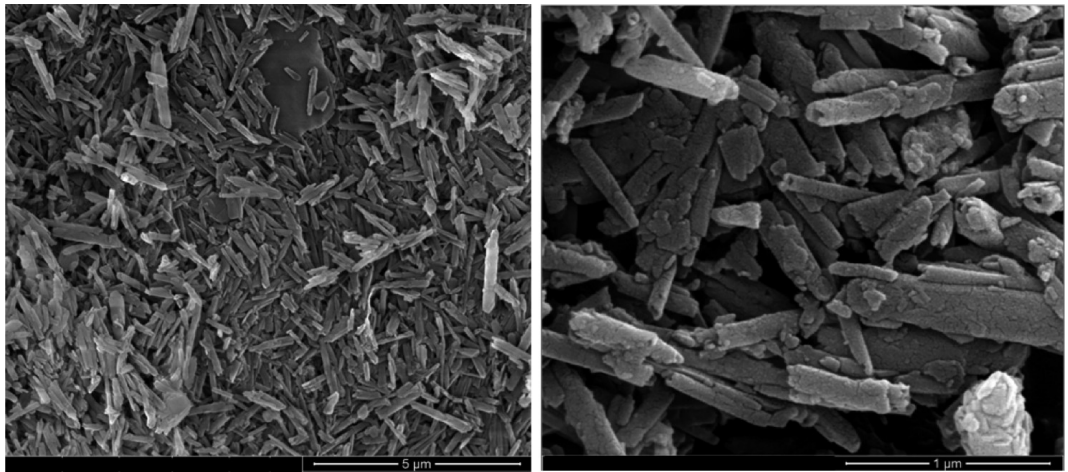

Figure 2. SEM micrographs for $\mathrm{HNT} / \mathrm{NaC} 14$.

selected because of their larger surfactant content (Figures 1 and 2).

The images show nanotubes with dimensions comparable to those of pristine HNTs. ${ }^{17}$ This means that the surfactant adsorption does not alter the tubular morphology. Moreover, the hollow cavity is preserved in the composite materials.

Once we ascertained that the nanotubes maintained their original shape during the fabrication of the hybrid materials, TGA analysis was done to make a quantitative computation of the amount of surfactant loaded into the lumen. To this end, preliminary thermograms of pure surfactants were determined (see the Supporting Information). The thermograms of the hybrid materials are very similar to that of pristine HNTs with the exception of the mass loss present over a range of temperatures, which is characteristic of surfactant degradation (Figure 3).

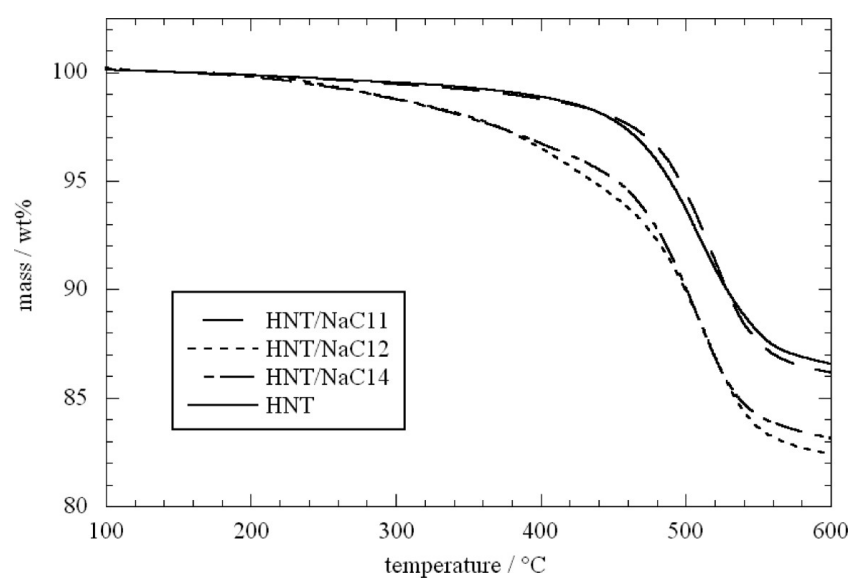

Figure 3. Thermograms of pristine and modified HNT.

The percent of surfactant in the composite $\left(C_{s}\right)$ was calculated by using the rule of mixtures ${ }^{17,18}$ once the mass loss of the pure components were known and by taking into account the water content calculated as the mass loss up to 150 ${ }^{\circ} \mathrm{C}$. In particular, the residual masses at $600{ }^{\circ} \mathrm{C}$ were used because the surfactant degradation can be considered complete. The results are reported in Table 1 .

It is noteworthy that anionic surfactant has to be loaded into the positive HNT lumen. ${ }^{14}$ The negative charge on the HNT outer surface definitely rules out the adsorption of the negatively charged surfactants. The maximum loading value expected from the cavity size is ca. $10 \%{ }^{3}$ The data in Table 1 show that for all of the surfactants this value is never reached,
Table 1. Percent of Water and Surfactant in the HNTs Cavity

$\begin{array}{ccc}\text { materials } & C_{\mathrm{s}}(\mathrm{wt} \%)^{a} & C_{\mathrm{w}}(\mathrm{wt} \%)^{a} \\ \mathrm{HNT} / \mathrm{NaC} 11 & 1.4 & 1.2 \\ \mathrm{HNT} / \mathrm{NaC} 12 & 8.0 & 0.5 \\ \mathrm{HNT} / \mathrm{NaC} 14 & 6.6 & 1.0 \\ { }^{a} \text { The error is } \pm 0.1 \text { wt } \% . & & \end{array}$

indicating the presence of void space in the hollow cavity. If one assumes that the adsorbed surfactant generates a monolayer, then by considering the average specific area of the inner surface ${ }^{19}\left(6.9 \mathrm{~m}^{2} \mathrm{~g}^{-1}\right)$ and the occupied area of the surfactant at the water/alumina interface ${ }^{20}\left(0.41 \mathrm{~nm}^{2}\right.$ molecule $\left.{ }^{-1}\right)$ a loading value of 1.2 wt $\%$ is calculated. From these results, one may deduce that $\mathrm{NaC} 11$ likely forms a monolayer in the lumen, whereas $\mathrm{NaC} 12$ and $\mathrm{NaC} 14$ generate structure that require larger amounts of surfactant.

The IR spectra of the hybrid materials exhibit characteristic bands of the two single components (spectra are reported in the Supporting Information) and evidence the presence of interactions between the surfactant and HNT.

The band of the symmetric stretching of $-\mathrm{CH}_{2}-$ in $\mathrm{NaCl1}$ and $\mathrm{NaC} 14$ is shifted toward larger values in the presence of nanotubes (Table 2). Such an effect was ascribed to the packing

Table 2. Stretching Values of the Surfactants and the Hybrid Materials

\begin{tabular}{lccc}
\multicolumn{1}{c}{ materials } & $\begin{array}{c}\mathrm{CH}_{2} \text { symmetric } \\
\text { stretching }\left(\mathrm{cm}^{-1}\right)\end{array}$ & $\begin{array}{c}\mathrm{C}=\mathrm{O} \\
\mathrm{CH}_{2} \text { asymmetric } \\
\text { stretching }\left(\mathrm{cm}^{-1}\right)\end{array}$ & $\begin{array}{c}\text { stretching } \\
\left(\mathrm{cm}^{-1}\right)\end{array}$ \\
$\mathrm{NaC11}$ & 2848 & 2923 & 1559 \\
$\mathrm{HNT} / \mathrm{NaC} 11$ & 2853 & 2923 & 1641 \\
$\mathrm{NaC14}$ & 2848 & 2921 & 1559 \\
$\mathrm{HNT} / \mathrm{NaC14}$ & 2851 & 2921 & 1633 \\
\hline
\end{tabular}

of the surfactant tails intercalated into the layers of HNTs. ${ }^{14}$ It is noteworthy that the stretching of $\mathrm{C}=\mathrm{O}$ undergoes substantial variations in the case of the hybrid materials. For both surfactants, the stretching undergoes a shift of ca. $80 \mathrm{~cm}^{-1}$, revealing interactions between the charged head of the surfactant and the opposite charge of the inner surface of the HNT. Similar changes were found for organic acids adsorption onto aluminum hydroxide, and they were explained by the formation of $\mathrm{C}-\mathrm{O}-\mathrm{Al}^{21}$

In summary, we have prepared hybrid materials of cylindrical shape containing a hydrophobic cavity. 
Stability of Aqueous HNTs/Surfactants Dispersions. Diffusion coefficients of $\mathrm{HNT} / \mathrm{NaC} 11, \mathrm{HNT} / \mathrm{NaC} 12$, and $\mathrm{HNT} / \mathrm{NaCl} 14$ in water as functions of the concentration of dispersed material were determined. The diffusion coefficient values are practically concentration-independent (see the Supporting Information) and follow the order $\mathrm{HNT} / \mathrm{NaC} 14$ $>\mathrm{HNT} / \mathrm{NaCl1}>\mathrm{HNT} / \mathrm{NaC} 12$. The $\mathrm{HNT} / \mathrm{NaC12}$ nanostructures present values for the translational average diffusion at infinite dilution $\left(D^{\circ}\right.$ in Table 3$)$ close to that reported for pristine HNTs in water. ${ }^{17}$

Table 3. Diffusion Coefficient and $\zeta$ Potential for HNT/ Surfactant Hybrid Materials

$\begin{array}{ccc}\text { materials } & D^{\circ} \times 10^{12}\left(\mathrm{~m}^{2} \mathrm{~s}^{-1}\right) & \zeta \text { potential }(\mathrm{mV}) \\ \mathrm{HNT} & 0.94^{a} & -19.4^{a} \\ \mathrm{HNT} / \mathrm{NaC} 11 & 1.04 \pm 0.01 & -28.3 \pm 0.4 \\ \mathrm{HNT} / \mathrm{NaCl2} & 0.88 \pm 0.02 & -25.3 \pm 0.2 \\ \mathrm{HNT} / \mathrm{NaC} 14 & 1.13 \pm 0.03 & -34.0 \pm 0.7 \\ { }^{a} \text { From ref } 14 . & & \end{array}$

The increase of $D^{\circ}$ for $\mathrm{HNT} / \mathrm{NaCl} 14$ and $\mathrm{HNT} / \mathrm{NaC} 11$ compared to the value of pristine HNTs demonstrates a larger mobility of these systems as a consequence of the functionalization. Such an increase cannot be ascribed to the reduction of the size of the nanoparticles, which is ruled out by the SEM experiments, but rather to the increment of the repulsions between the modified nanotubes because of the increase of the total charge. Insight into the charge of the modified nanotubes was provided by $\zeta$-potential measurements. The data in Table 3 show that the incorporation of anionic surfactant into the lumen generated a larger net negative charge of the HNT. It is noteworthy that the change of $\zeta$ potential with the nature of the incorporated surfactant follows $D^{\circ}$. These findings predict a better colloidal stability of the hybrid materials compared to the pristine nanotubes because of the low tendency to aggregate and the increased electrostatic repulsions between the particles.

To evaluate the mechanism controlling the dispersions stabilization, sedimentation experiments were done for pristine and functionalized HNTs in water using turbidimetry.

Figure 4 shows that the sedimentation is strongly slowed by the surfactant. The turbidity follows the same order as $D^{\circ}$ and $\zeta$

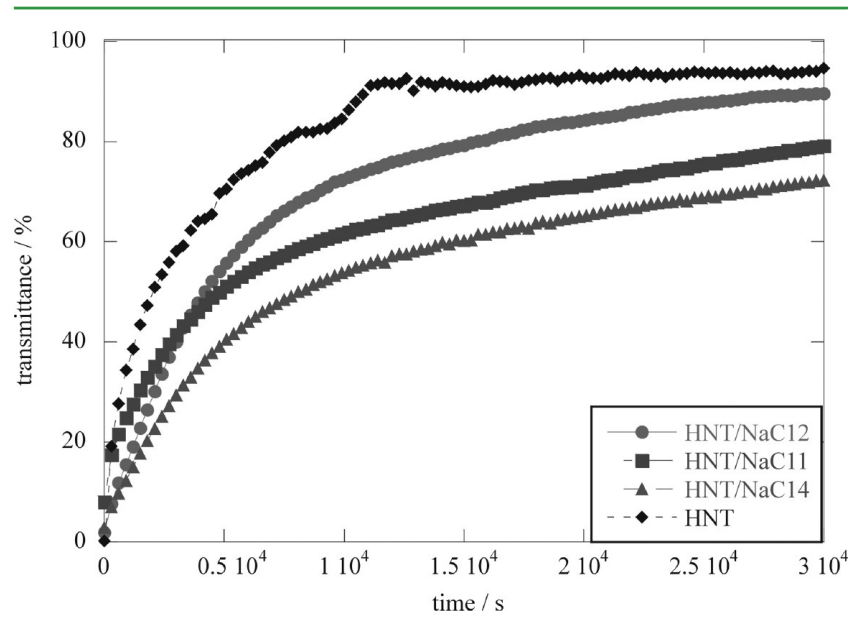

Figure 4. Transmittance at $600 \mathrm{~nm}$ as a function of time of pristine and modified HNT in water (1 wt \%). potential, namely, the higher the $D^{\circ}$ values and the more negative $\zeta$ potential, the more stable is the dispersion. These results prove that modification by means of anionic surfactants is an efficient strategy for the stabilization of HNTs dispersions; on the contrary, cationic surfactants generate destabilization, enhancing the sedimentation. ${ }^{14}$ The colloidal stability may also be confirmed by electrostatic effects because of the increment of the total net negative charge of the nanotube as a consequence of the neutralization of the positive charges of the inner surface subsequent to the surfactant adsorption.

It should be noted that the colloidal stability of modified HNTs is not strictly correlated to the loading degree (Table 1) for $\mathrm{HNT} / \mathrm{NaC} 12$ and $\mathrm{HNT} / \mathrm{NaC} 14$. However, the very high surfactant content into the lumen of close to $10 \%$ indicates the formation of surfactant self-organized structures in the cavity, for example, like double-layers that maintain the counterions and do not contribute to the charge increase of the nanoparticle and consequently to its electrostatic stabilization.

To study the crucial role of the electrostatic forces in controlling the stability of the aqueous dispersions of the hybrid HNTs, turbidity measurements were carried out at variable ionic strength. As the data in Figure 5 show, the modified nanotubes are highly destabilized by $\mathrm{KCl}$ because of the screening effect on the repulsive electrostatic forces between the nanoparticles.

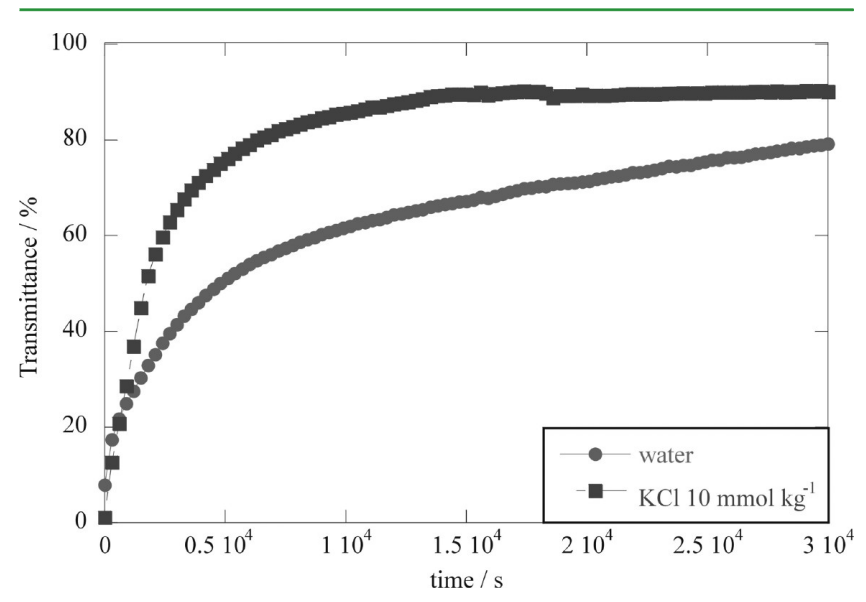

Figure 5. Transmittance at $600 \mathrm{~nm}$ as a function of time of HNT/ $\mathrm{NaC11}(1 \mathrm{wt} \%)$ in water and in $\mathrm{KCl}\left(10 \mathrm{mmol} \mathrm{kg}^{-1}\right)$.

This result agrees with the DLVO theory, which predicts that the stability of a colloidal system depends on both the attractive van der Waals forces and the electrostatic repulsive forces of the double layer surrounding each particle. ${ }^{22}$ This theory envisages that a large ionic strength generates a screening of the electrostatic repulsions because of the reduction of the double layer.

Inorganic Micelles Based on HNT for Encapsulating Oils. The structure as well as the chemistry of the HNTs makes them rather versatile. The goal of the selective modification of the inner surface is to obtain nanomaterials with controlled sizes and shapes with an enhanced hydrophilic surface and a hydrophobic core that may be exploited for encapsulation of molecular species to be removed from aqueous phases, to be delivered and released under control, and so on. In our work, we selected $n$-decane and toluene, which are organic compounds of environmental interest. $n$-Decane is an aliphatic hydrocarbon that is nearly immiscible with water ${ }^{23}$ (its 
solubility is $1.7 \times 10^{-7} \mathrm{~mol} \mathrm{~kg}{ }^{-1}$ ), whereas toluene is an aromatic hydrocarbon sparingly soluble in water ${ }^{24}$ (its solubility is $5 \times 10^{-3} \mathrm{~mol} \mathrm{~kg}^{-1}$ ). These nanohybrid materials will be employed as inorganic micelles to capture such compounds, and they will be examined in the solid state as well as in the aqueous dispersions.

Capturing Capability of $n$-Decane. We studied this hydrocarbon in the vapor and liquid phases, because its solubility in water is negligible. The HNT and the HNT/ surfactant powders were equilibrated in a desiccator saturated with $n$-decane vapors at a controlled temperature. The amount of entrapped $n$-decane was determined by TGA.

As Figure 6 shows, all of the materials exhibit a significant amount of adsorbed $n$-decane (grams of $n$-decane per $100 \mathrm{~g}$ of solid, $\left.Q_{\text {ads }}\right)$, which increases with temperature.

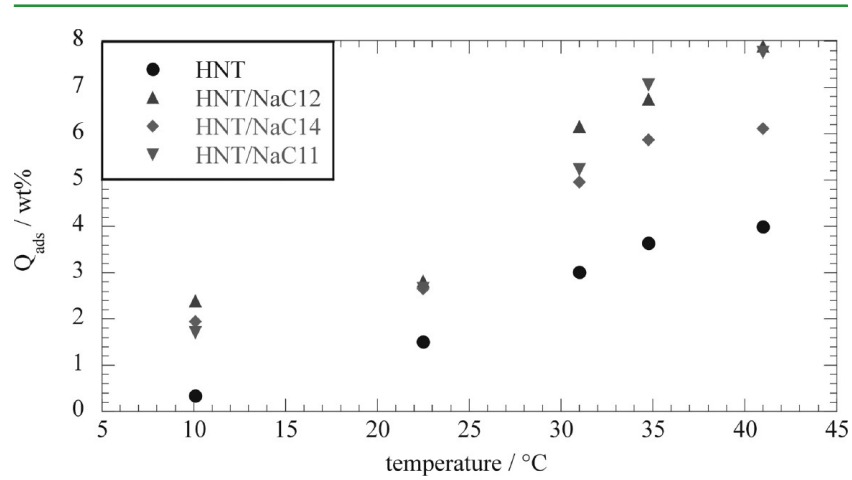

Figure 6. Quantity of $n$-decane adsorbed per $100 \mathrm{~g}$ of adsorbent as the temperature is changed.

From the data in Figure 6, one may argue that the hydrophobization of the HNT cavity improves the adsorption ability of the nanotubes and that this effect is independent of the alkyl chain length of the surfactant up to $30^{\circ} \mathrm{C}$. At higher temperatures, the hybrid materials containing $\mathrm{NaC} 11$ and $\mathrm{NaC} 12$ appear more efficient, which is rather surprising. Such a peculiar finding may be associated with two factors: (1) the change of the vapor pressure with temperature and consequently the $n$-decane concentration in the gas phase with temperature and (2) the temperature dependence of the equilibrium constant of adsorption. In the investigated temperature range, the vapor pressure $\left(P_{\text {vap }}\right)$ was calculated by means of the Antoine equation. ${ }^{25}$ The results demonstrate that the percent of $n$-decane volume in the vapor phase changes from 0.05 to $0.2 \mathrm{vol} \%$ upon changing the temperature from 10 to $42{ }^{\circ} \mathrm{C}$. Indeed, the thermodynamic property, which correctly and properly evidences the affinity of gaseous $n$-decane toward the solid phase, is represented by the adsorption constant $\left(K_{\mathrm{ads}}\right)$ calculated as

$$
K_{\mathrm{ads}}=Q_{\mathrm{ads}} / P_{\mathrm{vap}}
$$

The $K_{\text {ads }}$ values for all of the investigated systems are illustrated in Figure 7.

Temperature plays a negligible role on $K_{\mathrm{ads}}$ for all of the hybrid systems. The pristine nanotubes exhibit an affinity toward $n$-decane that is rather small at low temperatures and is definitely smaller than that of the hybrid materials. It is surprising that the adsorption ability of the hybrid materials does not depend on the alkyl chain length of the surfactants. This result is straightforward to comprehend if one considers that the thermodynamic properties reveal the interactions

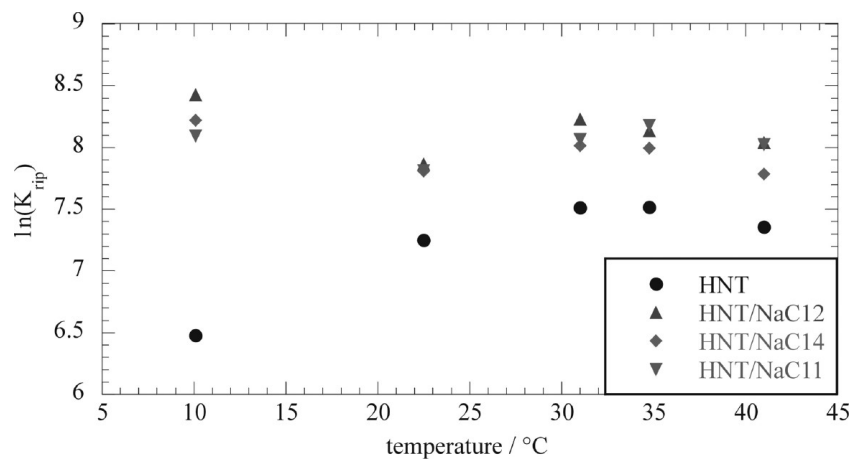

Figure 7. Adsorption constant of gaseous $n$-decane onto the solid substrate as a function of temperature.

exercised between the molecule and its environment in a state of equilibrium. ${ }^{26}$ In fact, in spite of the amount of surfactant as well as the surfactant-tail-dependent structures formed in the lumen, the structures nature remains unaltered (anhydrous and with properties similar to the hydrocarbons). Therefore, one may conclude that $\mathrm{HNT} / \mathrm{NaC} 11$ exhibits affinity toward gaseous $n$-decane in the same manner as $\mathrm{HNT} / \mathrm{NaC14}$ even though it contains a surfactant amount that is six times smaller than that in $\mathrm{HNT} / \mathrm{NaC} 14$. This result assumes a particular relevance for the potential uses of these materials as far as their cost benefit is concerned.

The liquid $n$-decane in contact with the aqueous phase mimes the case of an aquifer contaminated by light nonaqueous-phase liquids. The first experiments involved an aqueous phase with dispersed pristine HNTs (5 wt \%) and a film of $n$-decane $(0.4$ wt \%). Afterward, HNT/NaC14 and $\mathrm{HNT} / \mathrm{NaC} 11$ replaced the pristine HNTs. The $n$-decane/ nanomaterials ratio was selected from $Q_{\mathrm{ads}}$ data. In all cases, the surface tension as a function of time was measured under gentle stirring and controlled temperature. The results are illustrated in Figure 8.

The S-shaped trend registered for $\mathrm{HNT} / \mathrm{NaC} 14$ is peculiar, which exhibits a value of around $50 \mathrm{mN} \mathrm{m}^{-1}$ because of the presence of $n$-decane at the interface; for $7.5 \mathrm{~h}$ thereafter, it sharply increases, reaching the value of water $\left(72 \mathrm{mN} \mathrm{m}^{-1}\right)$. It is important to note that even very small amounts of $n$-decane at the interface drammatically lower the surface tension to a value of ca. $50 \mathrm{mN} \mathrm{m}^{-1}$. Therefore, such a jump reveals a disappearance of $n$-decane that may be attributed to evaporation and/or its entrapment into the hydrophobic cavity of the nanotube. The experiment in the presence of pristine HNTs revealed a nearly constant surface tension value of at least ca. $50 \mathrm{mN} \mathrm{m}^{-1}$ for $10 \mathrm{~h}$. Thus, one may state that the transferring of liquid $n$-decane to the aqueous nanotubes takes place only in the presence of $\mathrm{NaC} 14$ surfactant loaded into the lumen. However, such a process is strongly dependent on the alkyl chain length of the surfactant because $\mathrm{HNT} / \mathrm{NaC} 11$ (Figure 8) behaves like pristine HNTs.

From all of the experiments one may conclude that (1) ndecane at the interface does not evaporate over the experimental time window, (2) the adsorption onto the native HNTs is negligible, and (3) the efficiency of the hybrid HNT/ surfactant material is specific to the surfactant tail. In particular, the higher $\mathrm{NaC} 14$ surfactant loading produces complex structures in the lumen of HNTs that possess a more hydrophobic nature than the NaC11 monolayer. These structures may control the water capillary phenomenon into 


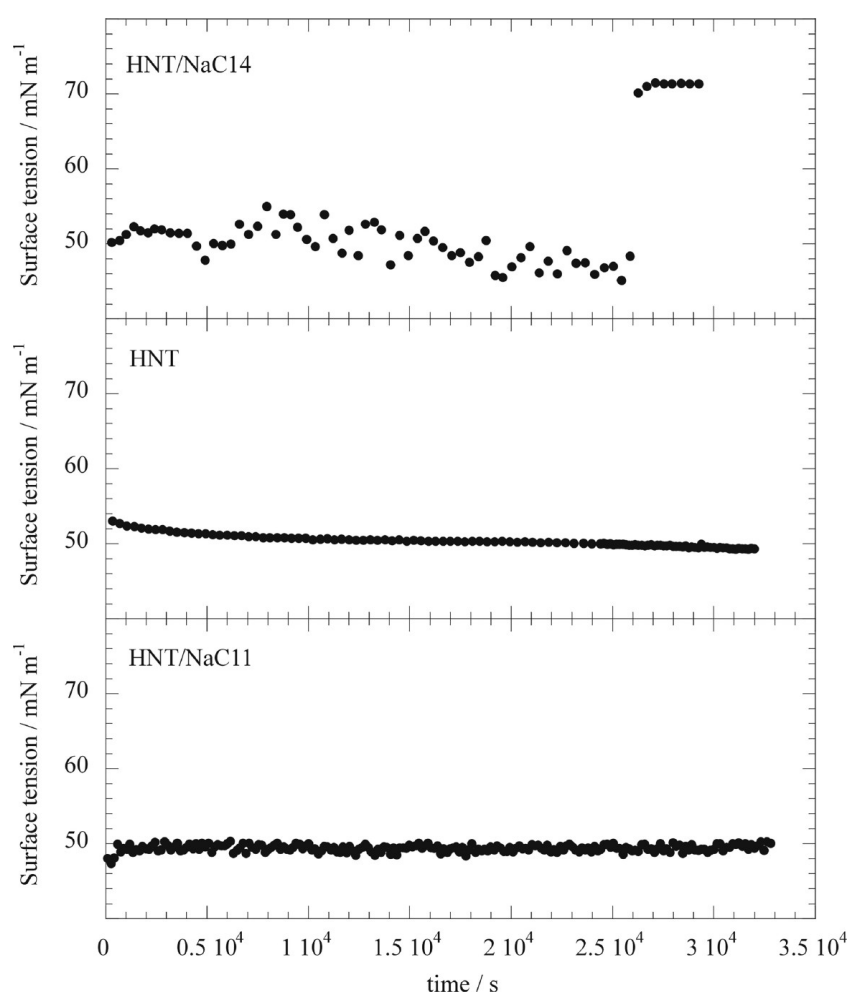

Figure 8. Surface tension as a function of time for aqueous HNT, $\mathrm{HNT} / \mathrm{NaC} 11$, and $\mathrm{HNT} / \mathrm{NaC} 14$ dispersions in the presence of an $n$ decane film.

the void space of nanotubes that is expected to be more important as the surfactant content becomes smaller. This behavior compared to that exhibited by the hybrid materials toward $n$-decane in the vapor phase indicates the relevant role played by the aqueous solvent in the transferring process.

Capturing Capability of Toluene. The inorganic micelles were also tested for their ability to entrap toluene solubilized in water at a concentration lower than its solubility. Figure 9 shows the difference of the removed toluene by the hybrid material with respect to the pristine HNT $(\Delta \mathrm{R})$. The surfactant tail tuned the affinity toward the oil; accordingly, higher alkyl chain surfactants exhibited a higher affinity toward toluene. Furthermore, the $\mathrm{HNT} / \mathrm{NaC} 11$ system does not improve the

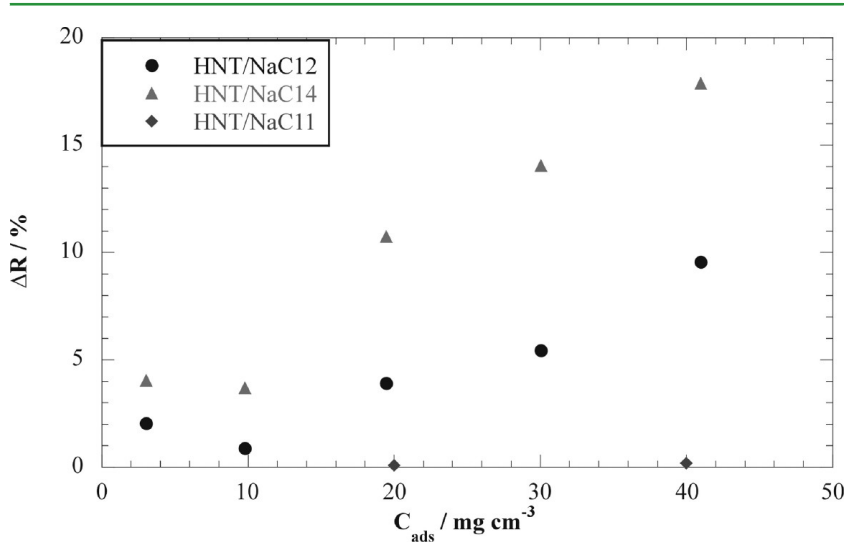

Figure 9. Toluene removal efficiency from aqueous dispersions of $\mathrm{HNT} / \mathrm{NaC} 11, \mathrm{HNT} / \mathrm{NaC} 12$, and $\mathrm{HNT} / \mathrm{NaC} 14$ calculated as a percentage increment with respect to the removal obtained by pristine HNT as a function of hybrid material concentration. encapsulation properties of HNTs at all. In spite of the loaded amount of $\mathrm{NaC} 12$ into the HNTs lumen being slightly larger than that of $\mathrm{NaC} 14, \mathrm{HNTs} / \mathrm{NaC} 14$ exhibits a larger solubilizing power, indicating that the formed complex structures, likely double layers, possess a hydrophobicity established by the alkyl chain length.

These results are in line with those obtained for the liquid $n$ decane solubilization, corroborating the findings that the surfactant monolayer of $\mathrm{HNT} / \mathrm{NaC} 11$ possesses a somewhat hydrophilic character, which is likely due to the presence of water, whereas the more complex surfactant structures of $\mathrm{HNT} / \mathrm{NaC1} 2$ and $\mathrm{HNT} / \mathrm{NaC} 14$ behave like conventional micelles. The impact and the significance that conventional micelles assume in various applications is well-known, for instance, the surfactant-enhanced aquifer remediation, solubilization, delivery, and release of drugs, and so on. Consequently, it is interesting to compare the solubilization power of such inorganic micelles with that of sodium alkanoates micelles in water. To this end, the concentration of the surfactant (molarity scale) into the inorganic micelles was calculated from the total concentration of the hybrid solid and the loading values (Table 1). For the most concentrated dispersion (40 mg $\mathrm{cm}^{-3}$ ) of the hybrid materials with the highest surfactant content ( $\mathrm{HNT} / \mathrm{NaC12})$, we obtained a surfactant concentration of $0.014 \mathrm{~mol} \mathrm{dm}^{-3}$. This value is rather intriguing as it is about one-half of the critical micellar concentration $(\mathrm{cmc})$ value of $\mathrm{NaC} 12$ in water. ${ }^{27}$ Keeping in mind that conventional surfactants enhance the solubility of oils in water only above the $\mathrm{cmc}^{26}$ where micelles take place, we can conclude that we successfully exploited the peculiar morphology of HNTs to prepare sustainable inorganic micelles with remarkable affinity toward oils that are sparingly soluble in water.

\section{CONCLUSIONS}

We developed a simple strategy to fabricate successfully HNT/ surfactant materials by the selective modification of the nanotubes inner cavity with anionic, hydrogenated surfactants with different length tails.

The objective of the selective functionalization was aimed at obtaining nanomaterials with an enhanced hydrophilic surface and a hydrophobic core. The net negative charge of the hybrid nanotubes allowed us to obtain stable colloids. The hydrophobization of the nanotube cavity was exploited for the entrapment of hydrocarbons, both aliphatic and aromatic, which can be removed from the aqueous and gas phases. In our work, interestingly, we proved that although the amount of loaded surfactant into the hybrid materials is lower than the surfactant critical micellar concentration the hybrid materials very efficiently behave like inorganic micelles for encapsulating oils.

\section{ASSOCIATED CONTENT}

\section{S Supporting Information}

Diffusion coefficient HNT/NaC11, HNT/NaC12, and HNT/ $\mathrm{NaC} 14$ in water as a function of concentration, FTIR spectra of $\mathrm{NaC} 11$ and $\mathrm{HNT} / \mathrm{NaC} 11$, and thermograms of $\mathrm{NaC} 11$, $\mathrm{NaC12}$, and $\mathrm{NaC14}$. This material is available free of charge via the Internet at http://pubs.acs.org.

\section{AUTHOR INFORMATION}

\section{Corresponding Author}

*E-mail: giuseppe.lazzara@unipa.it. 


\section{Notes}

The authors declare no competing financial interest.

\section{ACKNOWLEDGMENTS}

The work was financially supported by the University of Palermo, PRIN 2010-2011 (prot. 2010329WPF), FIRB 2012 (prot. RBFR12ETL5), and PON 2007-2013 STI-TAM.

\section{REFERENCES}

(1) Cradwick, P. D. G.; Farmer, V. C.; Russell, J. D.; Masson, C. R.; Wada, K.; Yoshinaga, N. Nature, Phys. Sci. 1972, 240, 187-189.

(2) Liu, W.; Chaurand, P.; Di Giorgio, C.; De Méo, M.; Thill, A.; Auffan, M.; Masion, A.; Borschneck, D.; Chaspoul, F.; Gallice, P.; Botta, A.; Bottero, J.-Y.; Rose, J. Chem. Res. Toxicol. 2012, 25, 25132522.

(3) Lvov, Y. M.; Shchukin, D. G.; Mohwald, H.; Price, R. R. ACS Nano 2008, 2, 814-820.

(4) Sciascia, L.; Turco Liveri, M. L.; Merli, M. Appl. Clay Sci. 2011, $53,657-668$.

(5) Luo, Z.; Song, H.; Feng, X.; Run, M.; Cui, H.; Wu, L.; Gao, J.; Wang, Z. Langmuir 2013, 29, 12358-12366.

(6) Vergaro, V.; Abdullayev, E.; Lvov, Y. M.; Zeitoun, A.; Cingolani, R.; Rinaldi, R.; Leporatti, S. Biomacromolecules 2010, 11, 820-826.

(7) Shchukin, D. G.; Lamaka, S. V.; Yasakau, K. A.; Zheludkevich, M. L.; Ferreira, M. G. S.; Mohwald, H. J. Phys. Chem. C 2008, 112, 958964.

(8) Abdullayev, E.; Price, R.; Shchukin, D.; Lvov, Y. ACS Appl. Mater. Interfaces 2009, 1, 1437-1443.

(9) Abdullayev, E.; Lvov, Y. J .Mater. Chem. 2010, 20, 6681-6687.

(10) Abdullayev, E.; Sakakibara, K.; Okamoto, K.; Wei, W.; Ariga, K.;

Lvov, Y. ACS Appl. Mater. Interfaces 2011, 3, 4040-4046.

(11) Lvov, Y.; Abdullayev, E. Prog. Polym. Sci. 2013, 38, 1690-1719.

(12) Shchukin, D. G.; Sukhorukov, G. B.; Price, R. R.; Lvov, Y. M. Small 2005, 1, 510-513.

(13) Yah, W. O.; Takahara, A.; Lvov, Y. M. J. Am. Chem. Soc. 2012, 134, 1853-1859.

(14) Cavallaro, G.; Lazzara, G.; Milioto, S. J. Phys. Chem. C 2012, 116, 21932-21938.

(15) Yah, W. O.; Takahara, A.; Lvov, Y. M. J. Am. Chem. Soc. 2011, 134, 1853-1859.

(16) Sidheswaran, P.; Bhat, A. N.; Ganguli, P. Clays Clay Miner. 1990, $38,29-32$.

(17) Cavallaro, G.; Lazzara, G.; Milioto, S. Langmuir 2011, 27, 11581167.

(18) Cavallaro, G.; Donato, D. I.; Lazzara, G.; Milioto, S. J. Phys. Chem. C 2011, 115, 20491-20498.

(19) Abdullayev, E.; Joshi, A.; Wei, W.; Zhao, Y.; Lvov, Y. ACS Nano 2012, 6, 7216-7226.

(20) Ruths, M.; Sjöblom, J.; Blokhus, A. M. J. Colloid Interface Sci. 1991, 145, 108-112.

(21) Guan, X. H.; Chen, G. H.; Shang, C. J. Environ Sci. 2007, 19, 438-443.

(22) Derjaguin, B. V.; Landau, L. D. Acta Physicochim. URSS 1941, 14, 733-762.

(23) Mackay, D.; Shiu, W. Y. J. Phys. Chem. Ref. Data 1981, 10, $1175-1199$.

(24) Neely, B. J.; Wagner, J.; Robinson, R. L.; Gasem, K. A. M. J. Chem. Eng. Data 2008, 53, 165-174.

(25) Carruth, G. F.; Kobayashi, R. J. Chem. Eng. Data 1973, 18, 115126.

(26) De Lisi, R.; Lazzara, G.; Milioto, S.; Muratore, N. J. Colloid Interface Sci. 2006, 300, 368-374.

(27) De Lisi, R.; Lazzara, G.; Milioto, S.; Muratore, N. Phys. Chem. Chem. Phys. 2003, 5, 5084-5090. 